\title{
Quality assessment of patients' self-monitoring of blood glucose in community pharmacies
}

\author{
Reidun L. S. KJOME, Anne G. GRANAS, Kari NERHUS, Sverre SANDBERG. \\ Received (first version): 1-Oct-2009 Accepted: 17-Jan-2010
}

\begin{abstract}
${ }^{*}$
Objective: To evaluate diabetes patients' selfmonitoring of blood glucose using a community pharmacy-based quality assurance procedure, to investigate whether the procedure improved the quality of the patient performance of self monitoring of blood glucose, and to examine the opinions of the patients taking part in the study.

Methods: The results of patient blood glucose measurements were compared to the results obtained with HemoCue Glucose $201^{+}$by pharmacy employees in 16 Norwegian community pharmacies. Patient performance was monitored using an eight item checklist. Patients whose blood glucose measurements differed from pharmacy measurements by more than $20 \%$ were instructed in the correct use of their glucometer. The patients then re-measured their blood glucose. If the results were still outside the set limits, the control procedure was repeated with a new lot of glucometer strips, and then with a new glucometer. The patients returned for a follow-up visit after three months.

Results: During the first visit, $5 \%$ of the 338 patients had measurements that deviated from pharmacy blood glucose values by more than $20 \%$ and user errors were observed for $50 \%$ of the patients. At the second visit, there was no significant change in the analytical quality of patient measurements, but the percentage of patients who made user errors had decreased to $29 \%(p<0.001)$. Eighty-five percent of the patients reported that they used their blood glucose results to adjust medication, exercise or meals. Fifty-one percent of the patients reported a greater trust in their measurements after the second visit. Eighty percent of patients wished to have their measurements assessed yearly. Of these patients, $83 \%$ preferred to have the assessment done at the community pharmacy.
\end{abstract}

\footnotetext{
*Reidun L. S. KJOME, Master of Pharmacy. Section for General Practice, Department of Public Health and Primary Health Care, University of Bergen. (Norway). Anne G. GRANAS, Master of Pharmacy, PhD, Associate professor. Centre for Pharmacy, Department of Public Health and Primary Health Care, University of Bergen. (Norway).

Kari NERHUS, BSc. Norwegian Centre for Quality Improvement of Primary Care Laboratories (NOKLUS), Section for General Practice, Department of Public Health and Primary Health Care, University of Bergen. (Norway). Sverre SANDBERG. MD, PhD, Professor. Head of Norwegian Centre for Quality Improvement of Primary Care Laboratories (NOKLUS), Section for General Practice, Department of Public Health and Primary Health Care, University of Bergen/ Head of Laboratory of Clinical Biochemistry, Haukeland University Hospital, Bergen (Norway).
}

Conclusion: A community pharmacy-based quality assessment procedure of patients' self monitoring of blood glucose significantly reduced the number of user errors. The analytical quality of the patients' measurements was good and did not improve further during the study. The high analytical quality might be explained by a selection bias of participating patients. Patients also reported increased confidence in their blood glucose measurements after their measurements had been assessed at the pharmacy.

Keywords: Blood Glucose Self-Monitoring. Quality Assurance, Health Care. Community Pharmacy Services. Norway.

\section{EVALUACIÓN DE LA CALIDAD DE LA AUTO-MONITORIZACIÓN DE GLUCOSA SANGUÍNEA DE PACIENTES EN FARMACIA COMUNITARIA}

\section{RESUMEN}

Objetivo: evaluar la auto-monitorización de la glucemia de pacientes diabéticos que utilizan un procedimiento de aseguramiento de la calidad en farmacia comunitaria, investigar si el procedimiento mejoró la calidad de la ejecución de la monitorización del paciente, y examinar las opiniones de los pacientes que tomaron parte en el estudio.

Métodos: Los resultados de las medidas de glucemia de los pacientes se compararon con los resultados obtenidos con un HemoCue Glucose 201+ por los empleados de la farmacia en 16 farmacias comunitarias noruegas. Se monitorizó la actuación del paciente utilizando un check-list de 8 puntos. Se educó en el uso del glucómetro a los pacientes cuyos valores de glicemia diferían en más de un $20 \%$ de los medidos en la farmacia. Después los pacientes volvieron a medir su glucemia. Si los resultados estaban aún fuera de los límites se repetía el procedimiento con un nuevo paquete de tiras de glucómetro, y después con un nuevo glucómetro. Los pacientes volvieron para una visita de seguimiento tres meses después.

Resultados: Durante la primera visita, el 5\% de los 338 pacientes tuvieron mediciones malas que se desviaron de las de la farmacia en valores superiores al $20 \%$ y se observaron errores en el $50 \%$ de los pacientes. En la segunda visita, no hubo cambios significativos en la calidad analítica de las medias de los pacientes, pero el porcentaje de usuarios con errores disminuyó al $29 \%(\mathrm{p}<0,001)$. El 85\% de los pacientes informó que utilizaban los resultados de su glucemia para ajustar la 
medicación, ejercicio o comidas. El $51 \%$ de los pacientes informó que tenían una mayor confianza en su medición después de la segunda visita. El $80 \%$ de los pacientes deseaba que se le evaluasen sus mediciones de glicemia anualmente. De estos pacientes, el $83 \%$ prefería que la evaluación se hiciese en la farmacia comunitaria.

Conclusión: Un procedimiento de evaluación de la calidad de la auto-monitorización de glucemia realizado en farmacia comunitaria redujo significativamente el número de errores de los usuarios. La calidad analítica de las medidas de los pacientes fue buena y no mejoró durante el estudio. La alta calidad analítica podría explicarse por un sesgo de selección de los pacientes participantes. Los pacientes también informaron e un aumento de confianza en sus medidas de glucemia después de que sus mediciones fueses evaluadas en la farmacia.

Palabras clave: Auto-monitorización de la glucemia. Aseguramiento de calidad en salud. Servicios de farmacia comunitaria. Noruega.

\section{INTRODUCTION}

Self-monitoring of blood glucose (SMBG) is considered essential in the management of diabetes. $^{1-5}$ The utility of the measurements depends on the analytical quality of the glucometers and strips ${ }^{6,7}$, patient performance of measurements ${ }^{2}$, and how the patients respond to the results. Studies of measurement quality report that $9-16 \%$ of patient SMBG-results deviate from laboratory results by more than $20 \% .^{8-11}$ Measurement quality is lower when glucometers are used by patients than by professionals. ${ }^{11}$ User error accounts for a considerable proportion of erroneous measurements. ${ }^{11-13}$ A study in German pharmacies found that $83 \%$ of patients made at least one SMBG user error. ${ }^{14}$ Some user errors, such as not washing hands or using expired strips, may lead to erroneous results. Other errors may impact the patients' compliance with SMBG, e.g. when patients fail to change lancets in their finger prick devices, leading to more painful measurements and patient reluctance. ${ }^{14}$ Regular assessments of patient SMBG measurements are necessary and broadly recommended ${ }^{1,2,4,15}$, but guidelines do not specify how or by whom these assessments should be carried out. Because user errors may lead to poor results it is important to check not only the instrument and strips but also patient performance. Glucometers have been shown to perform differently with control solution compared to blood $^{16,17}$, thus relying solely on control solution is not sufficient to ensure that the glucometer results are correct. Research shows that the few patients who perform some form of glucometer control usually do so by repeated measurements using a single glucometer or by comparing the results of two of their own glucometers ${ }^{11}$, but neither of these methods is satisfactory. Few studies have tested quality assured, accessible control services for glucometers and patient performance of SMBG. ${ }^{9,10,12}$ Neither teaching patients SMBG, nor evaluating patient performance is dedicated to one group of health professionals in Norway, and neither service is routinely offered to patients.

Diabetes patients visit community pharmacies on a regular basis, and most obtain their SMBG equipment there. Therefore the pharmacy might be well-suited for assessing meter accuracy and patient performance. ${ }^{18}$ However, to increase quality the assessment must be incorporated into an established system of quality assurance in which every link in the chain is assessed on a regular basis and educational feedback is provided. ${ }^{19}$

The aims of this study were (a) to assess the quality of Norwegian patients' SMBG measurements, (b) to investigate whether the quality and performance could be improved by establishing a control procedure at the community pharmacy and by giving educational feedback, and (c) to investigate patient opinions on receiving this service from their community pharmacy.

\section{METHODS}

Pharmacy recruitment: The study was performed in cooperation with one of the three main pharmacy chains in Norway, in order to ease the planning and the execution of the study. The pharmacy chain's professional service manager was asked to choose pharmacies suited for participation. Eighteen pharmacies were selected based on the inclusion criteria that the pharmacy must have suitable premises and at least one employee must have participated in continuing professional education courses on diabetes. This employee was responsible for conducting the study at the pharmacy and performing the SMBG assessments. Prior to study start two pharmacies withdrew from the study as the employee intended to be responsible for the study left, thus 16 pharmacies from 15 different Norwegian cities were included.

Patient recruitment: Men and women over 18 years of age with diabetes mellitus type 1 or 2 and who self-monitored blood glucose were recruited. There was no upper age limit, but patients in need of the assistance of a family member or community nurse to perform the measurements were excluded. A power-estimation showed that each pharmacy needed to include 26 patients (see "Statistics" below). A recruitment list was compiled of all customers who obtained SMBG equipment from the pharmacy during the previous six months. Invitations to take part in our study were sent to the first 55 people on the list fulfilling the inclusion criteria. Patients willing to participate were asked to return a signed consent form to the pharmacy and select a date and time for the SMBG assessment from time-slots suggested by the pharmacy. If fewer than 26 patients were recruited, invitations were sent to the next patients on the recruitment list. The patients were given identification numbers at the pharmacies, and names were not disclosed to the study coordinator. The study was approved by the 
National Committees for Research Ethics and by the Norwegian Social Science Data Services.

Assessment of glucometers and SMBG performance: To assess glucometers and SMBG performance we used a modified version of the procedure developed by Kristensen et al. ${ }^{10}$ for use in general practitioners' (GPs') offices. Patients brought their glucometers and strips to the pharmacy. When agreeing on a time for the patient visit the pharmacy employee gathered information on the type of glucometer used by the patient, and familiarized themselves with its use before seeing the patient. The first visit started with a structured interview to determine age, education, type of diabetes, medication use, last recalled $\mathrm{HbA} 1 \mathrm{c}-$ value, the patient's experiences with SMBG, and his or her use of the glucose results. The assessment procedure was as follows: The patients were asked to perform their blood glucose measurements as they would perform them at home. The employee assessed the performance according to a checklist consisting of eight items (Table 1). The checklist included items from the manufacturers' userinstructions expected to directly affect the result of the measurement, as well as performance-items regarded as "good practice". An example is pricking the side of the finger tip where there are less nerveendings. Failing to do so will not affect the result of the measurement, but may have a negative effect on compliance. ${ }^{14}$ For simplicity, failure to comply with any check-list item will in this paper be referred to as "user errors". If the employee observed any user errors, the patients were made aware of these and shown how to perform the task correctly. Within 5 minutes of the patient measurement, the pharmacy employee took a new sample from a different finger. The Norwegian Quality Improvement of Primary Care Laboratories (NOKLUS) has earlier performed studies that compared the precision of samples taken from a single finger with the precision of samples taken from different fingers, and could not find any difference when all samples were obtained within 5 minutes. Therefore sampling from different fingers has been the standard procedure in all subsequent studies. ${ }^{10,11,20}$ The pharmacy employee measured the patient's blood glucose using HemoCue Glucose 201+ (HemoCue AB, Ängelholm, Sweden), an instrument commonly used at general practitioners offices. If the difference between the pharmacy and patient's results exceeded $20 \%$ at glucose concentrations equal or over $4.2 \mathrm{mmol} / \mathrm{L}$ ( $75 \mathrm{mg} / \mathrm{dL})$ or $0.83 \mathrm{mmol} / \mathrm{L}$ (15 mg/dL) at glucose concentrations $<4.2 \mathrm{mmol} / \mathrm{L}^{21}$, the analytical quality of the measurement was considered unacceptable. The reason for the deviation was sought first in the patient's performance when making the measurement. The patient and employee then repeated their measurements. If the difference was still outside the preset limits, a fresh set of measurements was taken using a new lot of strips with the patient's glucometer. If still outside the set limits, the pharmacy provided a new glucometer of the same brand as the patient's. Patients that did not make user errors or have analytically unacceptable results did not receive any intervention regarding measurement technique.
The patients returned to the pharmacy approximately 3 months after their initial visit and the assessment procedure was repeated. At this stage the patients were interviewed about their experiences with the pharmacy blood glucose service.

Quality control of the new pharmacy service: The implementation of a quality ensured glucose method in the pharmacy is described in detail in a separate paper. ${ }^{22}$ The main findings will be stated here. The HemoCue Glucose 201+ was chosen for use at the pharmacies as it is a point-of-care instrument of high quality used by the majority of GP offices in Norway. Before and during the pharmacies' controls of patient SMBG, a quality control system was implemented to ensure traceability of the HemoCue Glucose 201+ method to a laboratory method traceable to the NIST 965 standard reference material. This quality control system consisted of four steps: 1) estimation of the variation between the HemoCue instruments to be used at the 16 pharmacies, 2) comparison of results from HemoCue with the results of a laboratory glucose method (Architect ci8200, Abbott Laboratories, Abbott Park, IL, USA) that was validated using the NIST standard reference material, 3) monitoring the quality of HemoCue by use of internal quality controls and 4) participation in an external quality assessment scheme provided by NOKLUS.

The between-instrument precision of the 16 instruments used by the pharmacies was judged satisfactory with an imprecision of $<2 \%$ in normal/high level of glucose and approximately $6 \%$ in low level. There was no significant bias between HemoCue and the laboratory method at the normal/high level of glucose (approximately 10 $\mathrm{mmol} / \mathrm{L}$ ) where most of the measurement results were found. The results of the external and internal quality controls were satisfactory throughout the study. ${ }^{22}$

All the pharmacy employees participated in a training program, including both individual work in the pharmacies and a common course day. At the end of the course day, the pharmacy employees carried out the whole patient control-procedure and their performance was assessed by the teachers. ${ }^{22}$

Statistics: The null hypothesis that the number of patients with unacceptable measurements would be the same on both the first and second visit was tested using the McNemar test for paired proportions, with alpha set to 0.05 (2-tailed) and power to 0.80. Based on earlier studies, the expectation was that approximately $15 \%$ of the patients would not achieve acceptable measurements on their first visit. ${ }^{8-10}$ The authors decided that the smallest improvement of interest was a reduction in the number of unacceptable measurements from $15 \%$ to $8 \%$. This calculation provided a proposed sample size of 291 patients. Assuming a dropout rate of $30 \%$ between the first and second visit, the participating pharmacies would have to recruit 416 patients, 26 patients per pharmacy. Estimating a response rate of approximately $50 \%$, each pharmacy was instructed to send invitations to 55 patients. Descriptive 
statistics for the continuous variables are expressed as median and range (min-max), whereas categorical variables are expressed as frequencies and/or percentages. The Pearson chi-square or, in the case of a $2 \times 2$ table, Fisher's exact test was used to test the patients' measurements for significant $(p<0.05)$ demographic and background variable effects. All tests were performed using SPSS 13 (SPSS Inc., Chicago, IL, USA), except the power estimate, which was performed using the statistical software Power and Precision version 2 (Biostat, Englewood, NJ, USA). their results to adjust medication, exercise, or meals. Table 3 shows which glucometers were used by the patients participating in our study.

Quality of the SMBG at baseline: Sixty-five percent of the patients obtained SMBG results within $10 \%$ of the pharmacies' results. Thirty percent of the patients' measurements deviated between $10 \%$ and $20 \%$. Five percent of measurements were of unacceptable analytical quality, that is to say they deviated by more than $20 \%$ from the HemoCue result, or, if the measurements were below 4.2 $\mathrm{mmol} / \mathrm{L}(75 \mathrm{mg} / \mathrm{dL})$, the difference exceeded 0.83

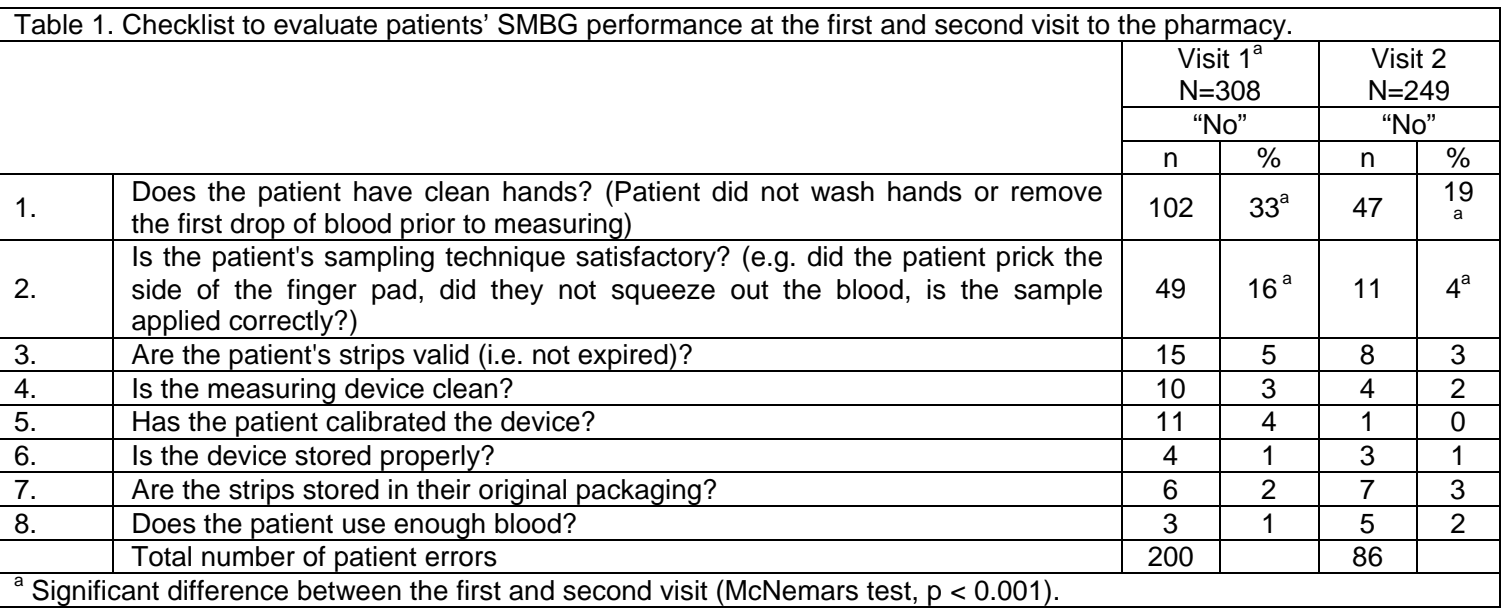

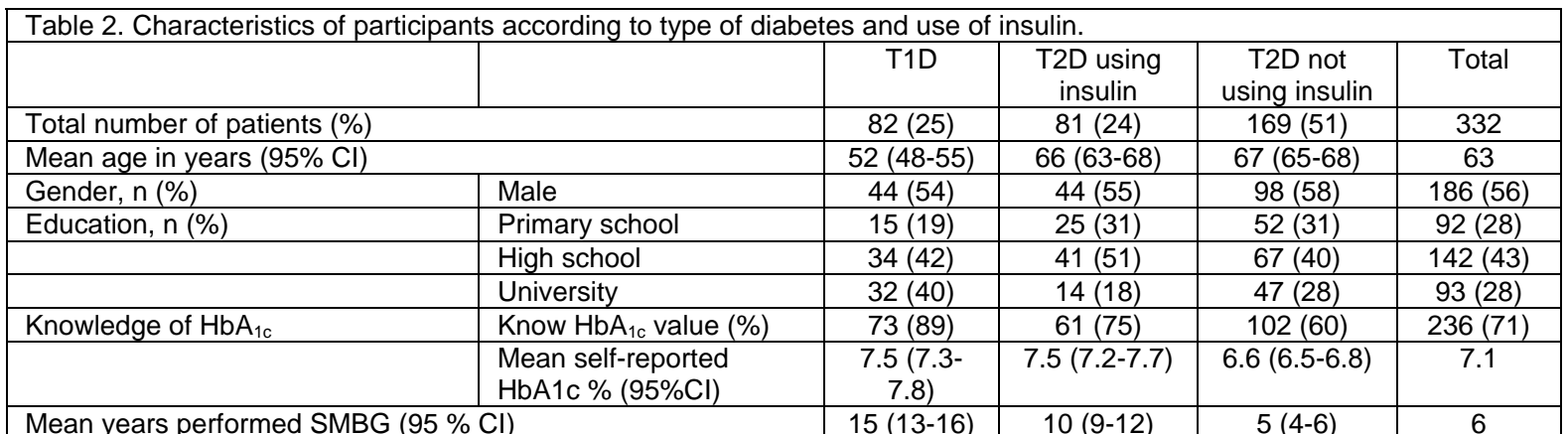

T1D, Type 1 diabetes; T2D, Type 2 diabetes. Six patients did not report type of diabetes and have been excluded from this table. Years and percents have been rounded to the nearest whole number. Where numbers do not add up to 100 , this is due to missing data and/or rounding.

\section{RESULTS}

The 16 pharmacies recruited 338 patients (9-32 patients per pharmacy) from the 1,146 invited patients, a response rate of $29 \%$. The response rate varied from 8 to $49 \%$ between pharmacies. Patient characteristics are reported in Table 2 . The majority of patients had type 2 diabetes (75\%), and $49 \%$ of all patients used insulin. Half of the patients reported their last measured $\mathrm{HbA} 1 \mathrm{c}$ value to be $7 \%$ or lower. The most frequent reason for the patients' choice of their current glucometer was a recommendation from pharmacy personnel (45\%). Forty-four percent of the patients were selfeducated in the SMBG, and $27 \%$ were taught at the pharmacy. The most frequently stated use of results from glucose measurements was to adjust meals based on the results (68\%). Forty percent used the results to adjust their medication, and $40 \%$ used them to adjust their exercise (multiple answers were possible). In total, $85 \%$ of the patients actively used $\mathrm{mmol} / \mathrm{L}(15 \mathrm{mg} / \mathrm{dL})^{21}$ (Figure 1).

At the first visit the pharmacy employees observed at least one user error in 156 of the patients (51\%) (one pharmacy did not use the checklist, thus $n=$ 308). The maximum number of user errors for one patient was three, and in total 200 user errors were registered. Table 1 shows the number of user errors per checklist item. Whether user errors were made by the patient did not predict the analytical quality of his or her measurement $(p=0.133)$. Though 156 patients made user errors, this resulted in an unacceptable quality for only 12 patients (8\%). Five of the 152 patients (3\%) who correctly performed the measurements had analytically unacceptable results.

Twenty five percent of the patients sometimes or often doubted the results of their own measurements (Table 4). Patients with type 1 diabetes were more confident in their results than those with type 2 diabetes $(p=0.039)$, and patients 
using insulin were more confident than those who do not $(p=0.016)$. Pearson chi-square tests showed that gender, age, education, type of diabetes, type of instrument, measurement frequency, whether patients feel unsure of their results, how results are employed, patient knowledge of the HbA1c value, self-reported $\mathrm{HbA} 1 \mathrm{c}$ value, and the use of drugs could predict neither measurements of acceptable analytical quality nor patient user errors. Patients stating that they were self-taught made significantly fewer patient user errors $(p=0.026)$.

Effects of the SMBG assessment: Between the first and second visit, 31 patients (9\%) dropped out of to 35 per 100 patients $(86 / 249)$ for the second visit. Because four of the pharmacies did not fill out the checklist at the second visit, the number of patients was reduced to 249 . The decrease in errors was still significant if only the 222 patients for whom the checklist was used at both visits were included ( $p<$ 0.001).

Follow-up of patients with unacceptable results: Of the 17 patients with analytically unacceptable measurements at the first visit, four measured outside the acceptable limits after receiving training from the pharmacy employee and measuring again.

\begin{tabular}{|l|c|}
\hline $\begin{array}{l}\text { Table 3. Glucometers used by the participating patients and number of patients using each } \\
\text { meter at the first visit to the pharmacy (glucometers are grouped by the type of strip they } \\
\text { use). }\end{array}$ \\
\hline \multicolumn{1}{|c|}{ Visit $1(\mathrm{n}=338)$} \\
\hline Accu-Chek Aviva & 28 \\
\hline Accu-Chek Sensor & 58 \\
\hline Accu-Chek Compact/Compact Plus & 56 \\
\hline Ascensia Elite/Elite XL & 31 \\
\hline Ascensia Breeze/Dex/Dex2 & 20 \\
\hline Ascensia Contour & 35 \\
\hline FreeStyle/FreeStyle Mini & 30 \\
\hline GlucoTouch & 2 \\
\hline InDuo/One Touch/One Touch Ultra/Ultra Smart & 27 \\
\hline MediSense Precision QID & 1 \\
\hline MediSense Precision Xceed/Xtra & 50 \\
\hline
\end{tabular}

\begin{tabular}{|c|c|c|c|c|c|}
\hline & & \multicolumn{2}{|c|}{ First visit } & \multicolumn{2}{|c|}{ Second visit } \\
\hline & & $\mathrm{n}$ & $\%$ & $\mathrm{n}$ & $\%$ \\
\hline \multirow{6}{*}{$\begin{array}{l}\text { Are you ever unsure that your device } \\
\text { shows the correct result? }\end{array}$} & Never & 150 & 45 & 193 & 67 \\
\hline & Rarely & 104 & 31 & 63 & 22 \\
\hline & Sometimes & 70 & 21 & 30 & 10 \\
\hline & Quite often & 11 & 3 & 2 & 1 \\
\hline & Almost every time I measure & 2 & 1 & 1 & 1 \\
\hline & Missing & 1 & & 49 & \\
\hline \multirow{4}{*}{$\begin{array}{l}\text { Following the controls at the } \\
\text { pharmacy, are you more or less sure } \\
\text { that your device shows the correct } \\
\text { result? }\end{array}$} & More sure & & & 157 & 51 \\
\hline & No change & & & 135 & 44 \\
\hline & Less sure & & & 14 & 5 \\
\hline & Missing & & & 49 & \\
\hline
\end{tabular}

the study, leaving 307 patients who completed both visits. Because the number of drop-outs was lower than we anticipated, the number of patients participating at both visits was sufficient according to our power calculation despite a lower recruitment than initially planned. However, because the percentage of analytically unacceptable measurements during the first visit was only $5 \%$, a decrease in analytically unacceptable measurements could not be expected. There was no significant change in the percentage of analytically unacceptable measurements from the first $(17 ; 5 \%)$ to the second $(19 ; 6 \%)$ visit (Figure 1 ). All 17 patients with unacceptable measurements at their first visit returned for a second visit. Only two of these patients had unacceptable results at the second visit. Table 1 presents the number of errors per checklist item during the first and second visit. During the second visit, the percentage of patients who made user errors had decreased from 51 to $29 \%$. The number of errors per patient varied from 0 to 2 , with the exception of one patient who made 5 errors. The total number of user errors decreased from 65 per 100 patients $(200 / 308)$ for the first visit
Two of the four patients obtained measurements within the limits when using strips with a new lot number, whereas the two remaining patients measured within the limits after receiving new strips and a new device. At the second visit, 11 of the 19 patients achieved acceptable quality with their second measurement. Of the remaining eight patients, four achieved acceptable results when using a new lot of strips and three when replacing both the strips and the device. Despite replacing both the strips and the glucometer, one patient still did not achieve acceptable results. A patient followup with a biomedical laboratory scientist concluded that the most likely explanation for these results was the patient's high hematocrit value, which is known to cause deviating blood glucose results. ${ }^{2}$

Patient satisfaction: Table 3 presents how the patients' trust in their measurements improved from the first to the second visit. A total of $80 \%$ of the patients returning for a second visit wished to have the SMBG assessments performed yearly. Of these patients, $83 \%$ preferred their community pharmacy as the site for the service, $5 \%$ preferred the hospital outpatient clinic, and $2 \%$ the GP's office. The 
remaining $10 \%$ of patients had no clear preferences. Thirty-two percent of the patients were prepared to pay up to 20 Euros for the service, and $50 \%$ were prepared to pay a maximum of 7.5 Euros. The remaining $18 \%$ of patients were not willing to pay for the service.
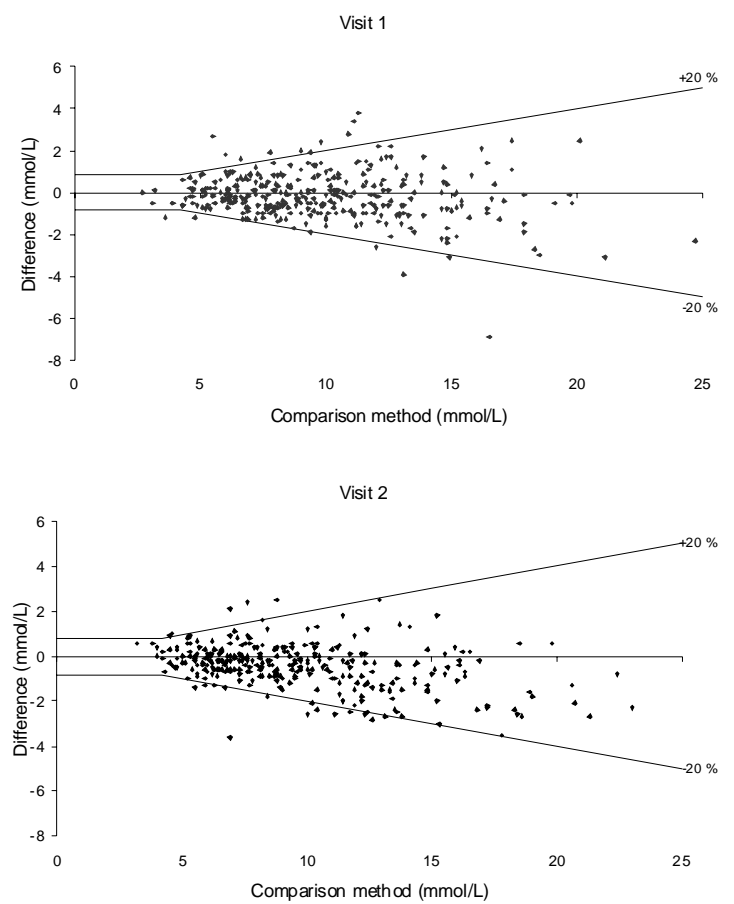

Figure 1. Difference between the patients' results and the pharmacies' results plotted against the results of the pharmacies at the first $(n=338)$ and the second $(n=304)$ visit. Lines represent limits recommended in ISO 15197: \pm $20 \%$ at glucose concentrations equal or over $4.2 \mathrm{mmol} / \mathrm{L}$ (75 mg/dL) and $\pm 0.83 \mathrm{mmol} / \mathrm{L}(15 \mathrm{mg} / \mathrm{dL})$ at glucose concentrations $<4.2 \mathrm{mmol} / \mathrm{L}(75 \mathrm{mg} / \mathrm{dL}){ }^{21}$

\section{DISCUSSION}

This study is unique in using community pharmacies as a site for the control of both the analytical quality of patients' measurements and the SMBG performance. In addition, the pharmacies benefitted from an established system of quality assurance through NOKLUS, thus continuously ensuring the quality of the pharmacy measurements. ${ }^{22}$ By performing the controls in this manner, followed by the correction of patient or instrument errors, this service has the potential to improve the quality of patient measurements, thereby improving patient management of diabetes. However, this also relies on patients reacting appropriately to the results of their SMBG measurements. Eighty-five percent of the patients reported that they used their measurement results actively to adjust medication, meals or exercise, but we have not investigated the appropriateness of these interventions in this study.

The analytical quality of patient measurements was considerably better in this study than reported in earlier studies. ${ }^{8-11}$ Because 15 of the 17 patients with unacceptable measurements at the first visit were replaced by 17 new patients with unacceptable measurements at the second visit, it is possible that the improvement seen with the original 15 patients was a result of regression to the mean rather than our intervention. ${ }^{23}$ The high analytical quality of the patients' SMBG in our study might be explained by a selection bias since the response rate was only $29 \%$, whereas other studies have considerably higher response rates. ${ }^{10}$ Patients willing to participating in the study were probably more motivated than the non-responders. The patients in our study had a self-reported mean $\mathrm{HbA} 1 \mathrm{c}$ of $7.1 \%$, close to the recommended $7 \%{ }^{1}$ and approximately 1 percentage point lower than the $\mathrm{HbA1c}$ of the patients in Skeie's study ${ }^{11}$, supporting the notion that the patients in our study are comparatively well regulated. Another factor may be that, following Skeie's study in $2002,{ }^{11}$ the Norwegian National Social Insurance Office required all manufacturers to have glucometers tested by patients. This requirement may have led to greater user-friendliness and more robust instruments. ${ }^{24}$

The percentage of patients with user errors (51\%) was lower than that reported in the German pharmacy study $(83 \%)^{20}$ but higher than in the Norwegian GPs' offices study (19\%). ${ }^{10}$ The number of user errors in our study was halved at the second visit compared to the first, a finding similar to that of Müller et al. ${ }^{14}$ It is difficult, however, to compare differences in the number of user errors between studies because the number of errors detected depends on the checklist used to uncover them. Müller et al. ${ }^{14}$ employed a highly detailed checklist compared to ours, which again was more detailed than the one used by Kristensen et al. ${ }^{10}$ In our study the most common user errors were not washing hands before measuring and poor sampling technique. It is possible that the fact that patients were aware that they were being assessed may have altered their performance, thus they avoided more "serious" user errors. The user errors we saw in our study did not lead to more measurements of unacceptable analytical quality; however, it is plausible that the correction of some errors will lead to better compliance. ${ }^{14}$ It would have been interesting to investigate whether specific errors affected the analytical quality, but the low number of unacceptable measurements in our study population did not allow for this.

Contrary to what one might assume, we found that patients who were self-taught made fewer user errors than those who had received SMBG training. Possibly, self-taught patients take a more active learning approach and study their glucometer manual more thoroughly compared to those who received training. Also, because the patients were not asked what their education entailed, the training in question might have been unsatisfactory, providing the patients who received it less information than the self-taught patients. It is not definite that one would see the same positive effect of no training in a less motivated patient group. Though the number of analytically unacceptable measurements was low in this study population, this does not change the fact that the quality of patients' SMBG measurements should be monitored. ${ }^{4}$ Our study found that the participating patients preferred 
to have their measurements assessed at their community pharmacy, and Norwegian pharmacy employees have also expressed an interest in working more actively in this field. ${ }^{25}$ In Norway the National Insurance Scheme pays for $90 \%$ of the expenses connected to diabetes patients' SMBG. In 2008 they spent more than 40 million Euros on glucometer strips alone. ${ }^{26}$ A service such as that we have described here could help ensure that this money is well spent; however a challenge for pharmacies considering implementation of a SMBG assessment service is to recruit patients most in the need of the service. Further studies should focus on recruiting patients with $\mathrm{HbA} 1 \mathrm{c}$ values above 7.5 $8 \%$.

\section{CONCLUSIONS}

Five percent of patient measurements deviated from the comparison method by more than $20 \%$. The analytical quality of the Norwegian diabetes patients' SMBG measurements was better than reported in earlier studies, possibly due to the selected patient sample. Fifty percent of the patients made user errors, but this did not lead to more unacceptable measurements. The pharmacy service significantly reduced the number of user errors and gave the patients more confidence in their measurements but did not improve the analytical quality of the measurements.

\section{ACKNOWLEDGEMENTS}

The authors thank HemoCue Norway (Ängelholm, Sweden) for providing instruments, microcuvettes, control material, and training to the pharmacies participating in the study. We thank Ms Åste Flatmark, chain professional service manager from Vitusapotek AS, for help planning the study and the 16 pharmacy employees for their hard work and enthusiasm. Thanks to biomedical laboratory scientists Åse Hirsch-Nilsen of NOKLUS and Grete Knudsen, Haukeland University Hospital, for help training the pharmacy employees. We also wish to thank Dr Gunn Kristensen, NOKLUS, for input regarding study design and practical help.

\section{CONFLICT OF INTEREST}

All HemoCue instruments and material were provided free of charge from HemoCue Norway. The pharmacy chain's professional service manager helped plan the study, but was not involved in analyzing the results, and the chain did not place any restrictions on the publishing or use of the results.

RLSK has received grants from Vitusapotek AS through the Norwegian Pharmacy Society's scholarship fund.

\section{References}

1. American Diabetes Association. Standards of medical care in diabetes -2008. Diabetes Care. 2008;31(Suppl 1):S12-S54.

2. Sacks DB, Bruns DE, Goldstein DE, Maclaren NK, McDonald JM, Parrott M. Guidelines and recommendations for laboratory analysis in the diagnosis and management of diabetes mellitus. Clin Chem. 2002;48(3):436-472.

3. Austin MM, Haas L, Johnson T, Parkin CG, Parkin CL, Spollett G et al. Self-monitoring of blood glucose: Benefits and utilization. Diabetes Educ. 2006;32(6):835-847.

4. Bergenstal RM, Gavin JR, III. The role of self-monitoring of blood glucose in the care of people with diabetes: report of a global consensus conference. Am J Med. 2005;118(Suppl 9A):1S-6S.

5. Foster SA, Goode JV, Small RE. Home blood glucose monitoring. Ann Pharmacother. 1999;33(3):355-363.

6. Rheney CC, Kirk JK. Performance of three blood glucose meters. Ann Pharmacother. 2000;34(3):317-321.

7. Ho SS, Nakahiro RK, Okamoto MP. Comparison of two brands of test strips for self-monitoring of blood glucose. Am J Health-Syst Pharm. 1997;54(9):1058-1062.

8. Alto WA, Meyer D, Schneid J, Bryson P, Kindig J. Assuring the accuracy of home glucose monitoring. J Am Board Fam Pract. 2002;15(1):1-6.

9. Bergenstal R, Pearson J, Cembrowski GS, Bina D, Davidson J, List S. Identifying variables associated with inaccurate self-monitoring of blood glucose: proposed guidelines to improve accuracy. Diabetes Educ. 2000;26(6):981-989.

10. Kristensen GBB, Nerhus K, Skeie S, Sandberg S. Quality Assurance of Self-monitoring of Blood Glucose at the General Practitioner's Office. Point of Care. 2006;5(3):100-104.

11. Skeie S, Thue G, Nerhus K, Sandberg S. Instruments for self-monitoring of blood glucose: Comparisons of testing quality achieved by patients and a technician. Clin Chem. 2002;48(7):994-1003.

12. Eye KL, Janney L. Identification of need for education in self-monitoring of blood glucose. Am J Health-Syst Pharm. 1996;53(12):1456-1457.

13. Nettles A. User error in blood glucose monitoring. The National Steering Committee for Quality Assurance Report. Diabetes Care. 1993;16(6):946-948.

14. Müller U, Hämmerlein A, Casper A, Schulz M. Community pharmacy-based intervention to improve self-monitoring of blood glucose in type 2 diabetic patients. Pharm Pract (Internet). 2006;4(4):195-203.

15. Barlow I, Beer S, Summerton N. Meta-analysis of diabetes care in general practice. All glucose meters must be subject to formal quality control measures. BMJ. 1999;318(7181):460

16. Kristensen GB, Christensen NG, Thue G, Sandberg S. Between-lot variation in external quality assessment of glucose: clinical importance and effect on participant performance evaluation. Clin Chem. 2005;51(9):1632-1636.

17. Johnson RN, Baker JR. Error detection and measurement in glucose monitors. Clin Chim Acta. 2001;307(1-2):61-67.

18. Storimans MJ, Klungel OH, Talsma H, Bouvy ML, de Blaey CJ. Collaborative services among community pharmacies for patients with diabetes. Ann Pharmacother. 2005;39(10):1647-1653. 
19. Price CP. Point of care testing. BMJ 2001;322(7297):1285-1288.

20. Kristensen GBB, Nerhus K, Thue G, Sandberg S. Standardized evaluation of instruments for self-monitoring of blood glucose by patients and a technologist. Clin Chem. 2004;50(6):1068-1071.

21. ISO. In vitro diagnostic test systems - requirements for blood glucose monitoring systems for self-testing in managing diabetes mellitus. ISO/TC 212/SC. International Standard ISO 15197, 2003. International Standard ISO 15197 ed. Geneva, Switzerland.: 2003.

22. Kjome RLS, Nerhus K, Sandberg S. Implementation of a method for glucose measurements in community pharmacies. Int J Pharm Pract. 2010;18(1):13-19.

23. Davis CE. The effect of regression to the mean in epidemiologic and clinical studies. Am J Epidemiol. 1976;104(5):493498.

24. Kristensen GB, Monsen G, Skeie S, Sandberg S. Standardized evaluation of nine instruments for self-monitoring of blood glucose. Diabetes Technol Ther. 2008;10(6):467-477.

25. Kjome RL, Sandberg S, Granas AG. Diabetes care in Norwegian pharmacies: a descriptive study. Pharm World Sci 2008;30(2):191-198.

26. The Norwegian Pharmacy Association [homepage on the internet]. Bransjestatistikk [Trade statistics]. http://www.apotek.no/graphics/NAF-bibliotek/Statistikk/apolegemidl09.pdf (accessed September 1st 2009) [in Norwegian]. 